\title{
Digestibilidade Aparente da Energia e Nutrientes do Farelo de Canola pela Tilápia do Nilo (Oreochromis niloticus)
}

\author{
Wilson Massamitu Furuya1, Luiz Edivaldo Pezzato², Edma Carvalho de Miranda1, Valéria \\ Rossetto Barriviera Furuya ${ }^{3}$, Margarida Maria Barros ${ }^{4}$, Eduardo Arruda Teixeira Lanna ${ }^{5}$
}

RESUMO - Este estudo foi realizado para determinar a energia digestível e a digestibilidade aparente de nutrientes do farelo de canola pela tilápia do Nilo (Oreochromis niloticus). O óxido de crômio $(0,1 \%)$ foi utilizado como indicador inerte em dieta semi-purificada, com coleta de fezes pelo sistema Guelph. Os peixes foram alimentados até saciedade aparente. $O$ farelo de canola apresentou valores de energia e nutrientes digestíveis de: 77,84; 71,99;86,92; 88,19; 67,16 e 29,86\% para a matéria seca, energia, proteína, lipídios, cálcio e fósforo, respectivamente, correspondendo a 2969,98 (kcal/kg); 69,97; 32,6; 1,2; 0,41 e 0,28\%, de energia digestível, matéria seca, proteína e lipídios digestíveis e cálcio e fósforo disponíveis, respectivamente. Os resultados obtidos neste trabalho evidenciam que a tilápia do Nilo pode utilizar eficientemente o farelo de canola.

Palavras-chave: digestibilidade aparente, farelo de canola, Oreochromis niloticus, tilápia do Nilo

\section{Apparent Nutrient and Energy Digestibility of Canola Meal for Nile Tilapia (Oreochromis niloticus)}

\begin{abstract}
This study was carried out to determine the digestible energy and apparent nutrient digestibility of canola meal for Nile tilapia (Oreochromis niloticus). The chromic oxide $(0.1 \%)$ was used as an inert indicador in the semi-purified diet and faeces were collected by Guelph system. Fish were fed to apparent satiation. The apparent nutrient and energy digestibility of canola meal were: $77.84,71.99$, $86.92,88.19,67.16$, and $29.86 \%$ for dry matter, energy, protein, lipids, calcium and phosphorus, respectively, corresponding to 2969,98 $(\mathrm{kcal} / \mathrm{kg}) ; 69.97,32.6,1.2,0.41$, and $0.28 \%$ of, digestible energy, dry matter, protein and lipids and available calcium and phosphorus, respectively. The results obtained in this experiment evidence that Nile tilapia may be able to utilize canola meal eficiently.
\end{abstract}

Key Words: apparent digestibility, canola meal, Nile tilapia, Oreochromis niloticus

\section{Introdução}

As tilápias utilizam eficientemente dietas com elevados níveis de carboidratos (STICKNEY, 1997), atribuído às adaptações morfológicas e fisiológicas, que incluem dentes faringeanos, $\mathrm{pH}$ estomacal baixo $(<1,5)$ e intestino longo (KUBARIK, 1997).

A canola é uma oleaginosa melhorada da colza, que possui baixos níveis de glicosinolatos na semente $(<3 \mu \mathrm{g} / \mathrm{g})$ e de ácido erúcico no óleo $(<2 \%)$ (BELL, 1993). Seu cultivo vem aumentando a cada ano na região Sul como opção de cultura de inverno, objetivando a produção de óleo rico em ácidos graxos insaturados (SANTOS e BASSO, 1990).

O farelo de canola (FC) é o subproduto obtido da extração do óleo da semente da canola (MUZTAR e SLINGER, 1982), apresenta maior teor de matéria seca, aminoácidos sulfurados, extrato etéreo, fibra bruta, cálcio, fósforo total (BELL e KEITH, 1991) e vitaminas do complexo B (colina, niacina, tiamina, riboflavina, ácido fólico e biotina), em relação ao farelo de soja (BELL, 1993). Entretanto, possui fatores limitantes como os metabólitos oriundos da hidrólise dos glicosinolatos, inibidores de tripsina, fitatos, compostos fenólicos e taninos (TESKEREDZIC et al., 1995). Em relação ao farelo de soja, possui maior nível de aminoácidos sulfurados e fósforo total (FURUYA et al., 1999), além do menor custo (30\%) em relação ao farelo de soja (FURUYA et al., 1997).

A determinação do coeficiente de digestibilidade aparente (CDA) foi investigada a partir da década de 70 para diversas espécies de peixes e, recentemente, destacam-se os trabalhos de HAJEN et al. (1993), YAMAMOTO et al. (1997) e SUGIURA et al.

\footnotetext{
${ }^{1}$ Prof. M.Sc. da Univ. Est. de Maringá, Depto. de Zootecnia, 87020-900, Maringá - PR. E.mail: furuya@wnet.com.br

2 Prof. Dr., Depto. de Melhoramento e Nutrição Animal, FMVZ/UNESP/Botucatu - SP, Brasil.

${ }^{3}$ Doutoranda, Universidade Estadual de Maringá, DBI, Maringá, PR, Brasil.

4 Zootecnista, FMVZ/UNESP/Botucatu - SP, Brasil.

5 Prof. Dr., Depto. de Zootecnia, UFV/Viçosa - MG, Brasil.
} 
(1998) com salmonídeos, WILSON e POE (1985) e KHAN (1994) com os bagres, DEGANI et al. (1997) e ERFANULLAH-JAFRI (1998) com as carpas e HANLEY (1987) e FAGBENRO (1998) com as tilápias. De forma geral, os trabalhos têm demonstrado baixa eficiência na utilização da energia dos ingredientes de origem vegetal pelas espécies de clima tropical ou temperado. Entre as espécies onívoras de água doce, as tilápias têm se destacado nos estudos de digestibilidade envolvendo fontes protéicas de origem vegetal, como pode ser observado no trabalho de DEGANI e REVACH (1991), que demonstraram maior eficiência da tilápia (Oreochromis aureus x O. niloticus) em utilizar a energia de dietas ricas em carboidratos, em comparação com a carpa comum (Cyprinus carpio) e o bagre africano (Clarias gariepinus), fato que também pode ser observado nos trabalhos de HANLEY (1987), DEGANI et al. (1997) e FAGBENRO (1998).

Poucos são os trabalhos realizados com o objetivo de determinar a energia digestível e o CDA de nutrientes do FC para peixes. HILTON e SLINGER (1986), em estudo realizado com alevinos de truta arco-íris (Oncorhynchus mykiss), encontraram valores de CDA de 60,4; 75,4; 87,1 e 92,5\% para matéria seca, energia, proteína e lipídios, respectivamente. Valores próximos de CDA da proteína foram obtidos por HOSSAIN e JAUNCEY (1989) com a carpa comum, de 85,3\%, e por ANDERSON et al. (1992) com o salmão (Salmo salar), de 74,1\%, aproximando-se do CDA da proteína $(87,9 \%)$ observado por HAJEN et al. (1993) com juvenis de salmão (Oncorhynchus tshawytscha). Os autores consideraram que o baixo CDA da matéria seca foi atribuído ao nível de fibra bruta, de $11 \%$ (base na matéria seca), que diminuiu o tempo de permanência da digesta e reduziu a utilização da energia e nutrientes.

Em estudo realizado com alevinos de "rohu" (Labeo rohita), HOSSAIN et al. (1997) encontraram valores de CDA de 91,95\% para os lipídios da mostarda, aproximando-se do valor descrito por DEGANI et al. (1997), com os lipídios do farelo de soja, de $90,44 \%$, obtido com a tilápia híbrida (Oreochromis niloticus x $O$. aureus).

A disponibilidade do fósforo é bastante limitada nos ingredientes de origem vegetal, uma vez que se encontra na forma de fitato, não disponível aos animais não-ruminantes (SUGIURA et al., 1999). RICHIE e BROWN (1996) determinaram um nível de fitato de 63,$1 ; 81,7$ e 56,3\% para os farelos de algodão, soja e canola, respectivamente, o que leva à necessidade de suplementação com fósforo inorgânico para se obter adequado desempenho (SUGIURA et al., 1999).

Pela sua disponibilidade em algumas regiões e menor custo em relação ao farelo de soja (30\%), justificam-se os estudos para determinar a energia digestível e o CDA de nutrientes desse ingrediente, visando reduzir o custo com alimentação. Assim, o objetivo do presente trabalho foi determinar a energia digestível e a digestibilidade aparente de nutrientes do farelo de canola pela tilápia do Nilo (Oreochromis niloticus).

\section{Material e Métodos}

O presente trabalho foi realizado no Laboratório de Nutrição de Organismos Aquáticos, da Faculdade de Medicina Veterinária e Zootecnia, UNESP - Campus de Botucatu-SP, Unidade Integrada do Centro de Aquicultura da UNESP, no período de 25 de setembro a 10 de novembro de 1998 .

Foram utilizadas 120 tilápias do Nilo, revertidas durante a fase larval, utilizando-se $60 \mathrm{mg}$ do hormônio $17 \alpha$-metiltestosterona $/ \mathrm{kg}$ de dieta, com peso vivo médio de 25,24 $\pm 3,88 \mathrm{~g}$, distribuídas em duas gaiolas cilíndricas de tela plástica, com volume útil individual de $70 \mathrm{~L}$, mantidas das 9 às $19 \mathrm{~h}$ em aquários de alimentação $(230 \mathrm{~L}) \mathrm{e}$, posteriormente, transferidas para aquário de coleta $(120 \mathrm{~L})$, sendo ambos mantidos com um sistema de aeração, por meio de pedra porosa acoplada a um aerador central e biofiltro.

A temperatura, oxigênio dissolvido e amônia foram monitoradas diariamente às 8 e $17 \mathrm{~h}$. Foi utilizado aquecedor de 100 Watts para manter a temperatura da água dos aquários de coleta e de alimentação entre 25 a $27^{\circ} \mathrm{C}$. O nível de amônia foi monitorado e mantido em níveis abaixo de $0,10 \mathrm{mg} / \mathrm{L}$, por sifonagem e reposição de água.

Para a determinação da digestibilidade, foi utilizada dieta referência purificada formulada com base em proteína da albumina e gelatina (Tabela 1).

Para confecção das dietas, após pesagem e homogeneização dos ingredientes, foi adicionada água $\left(45^{\circ} \mathrm{C}\right)$ na proporção de $12 \%$ sobre seu peso total e, em seguida, peletizadas em moinho de carne e desidratada em estufa de ventilação forçada $\left(45^{\circ} \mathrm{C}\right)$, durante um período de $18 \mathrm{~h}$. Após, foram mantidas em geladeira $\left(5^{\circ} \mathrm{C}\right)$ durante um período de $2 \mathrm{~h}$ e, em seguida, desintegradas em quebrador e peneiradas, sendo selecionados os grânulos com diâmetros entre 2 e $5 \mathrm{~mm}$.

Foi realizado período de adaptação de seis dias às instalações, manejo e dietas experimentais. Os ani- 
Rev. bras. zootec.

Tabela 1 - Composição percentual da dieta referência (base na matéria natural)

Table 1 - Percentual composition of reference diet (as fed basis)

\begin{tabular}{|c|c|}
\hline $\begin{array}{l}\text { Ingredientes } \\
\text { Ingredients }\end{array}$ & $\%$ \\
\hline Albumina & 32,00 \\
\hline Albumin & \\
\hline Gelatina & 7,70 \\
\hline Gelatin & \\
\hline Amido de milho & 44,13 \\
\hline Corn starch & \\
\hline Óleo de soja & 6,00 \\
\hline $\begin{array}{l}\text { Soybeanoil } \\
\text { a - celulose }\end{array}$ & 6,00 \\
\hline$a-$ cellulose & \\
\hline Fosfato bicálcico & 3,00 \\
\hline Dicalcium phosphate & \\
\hline Premix min. e vitamínico ${ }^{2}$ & 0,50 \\
\hline Mineral and vitamin mix & \\
\hline Vitamina $C^{3}$ & 0,05 \\
\hline Vitamin $C$ & \\
\hline Sal comum & 0,50 \\
\hline Salt & \\
\hline $\mathrm{BHT}^{4}$ & 0,02 \\
\hline Óxido de crômio ${ }^{5}$ & 0,10 \\
\hline Chromic oxide & \\
\hline Total & 100,00 \\
\hline
\end{tabular}

1 a-celulose (a - cellulose): energia bruta (gross energy) = 3658,86 kcal $/ \mathrm{kg}$; proteína bruta (crude protein) $=1,8 \%$; fibra bruta (crude fiber) $=72,91 \%$; cálcio (Calcium) $=0,28 \%$ e fósforo total $($ Total phosphorus $)=0,08 \%$.

2 Premix min. e vit. (mineral and vitamin mix) (Supremais, Campinas-SP): Composição por quilo de produto (composition per $\mathrm{kg}$ the product): Vit. $A=1.200 .000 \mathrm{UI}$; vit. $\mathrm{D}_{3}=200.000 \mathrm{UI}$; vit. $E=12.000 \mathrm{mg}$; vit. $K_{3}=2400 \mathrm{mg}$; vit. $B_{1}=4800 \mathrm{mg}$; vit. $B_{2}=4800 \mathrm{mg} ;$ vit. $B_{6}=4000 \mathrm{mg}$; vit. $B_{12}=4800 \mathrm{mg}$; ác. fólico (folic acid $)=1200 \mathrm{mg}$; pantotenato de cálcio (calcium pantothenate) $=12.000 \mathrm{mg}$; vit. $\mathrm{C}=48.000 \mathrm{mg}$; biotina (biotin) $=48 \mathrm{mg}$; colina (choline) $=65.000 \mathrm{mg}$; ácido nicotínico (nicotinic acid) $=24.000 \mathrm{mg} ; \mathrm{Fe}=10.000 \mathrm{mg} ; \mathrm{Cu}=600 \mathrm{mg} ; \mathrm{Mn}=4000 \mathrm{mg}$; $\mathrm{Zn}=6000 \mathrm{mg} ; \mathrm{I}=20 \mathrm{mg} ; \mathrm{Co}=2 \mathrm{mg}$ e Se $=20 \mathrm{mg}$.

3 Vit. C (Basf, São Paulo-SP): sal cálcica 2-monofosfato de ácido ascórbico, $42 \%$ de princípio ativo (calcic salt, ascorbic acid 2-monophosphate - $42 \%$ active principle).

${ }^{4}$ Butil-Hidroxi-tolueno (Butyl-hydroxi-toluen).

5 Óxido de crômio $\left(\mathrm{Cr}_{2} \mathrm{O}_{3}\right)$ (Chromic oxide).

mais foram arraçoados a cada duas horas, das 9 às $18 \mathrm{~h}$, manualmente, e até saciedade aparente, quando não foi observada captura dos grânulos fornecidos durante o seu deslocamento da superfície até o fundo dos aquários de alimentação.

A coleta de fezes foi realizada diariamente, às $8 \mathrm{~h}$, e posteriormente centrifugadas durante $10 \mathrm{~min}$. a $2500 \mathrm{rpm}$. O sobrenadante foi desprezado e o material precipitado, desidratado em estufa de renovação e circulação de ar a $50^{\circ} \mathrm{C}$, durante um período de 18 horas. Após secagem, o material foi moído em moinho criogênico, identificado e armazenado em refrigerador para posterior análise. Diariamente, após a retirada dos peixes dos aquários de digestibilidade e de alimentação, as fezes e sobras de dietas foram retiradas por meio de sifonagem. Considerou-se como repetição o "pool" de duas coletas.

As análises químico-bromatológicas dos alimentos e das dietas foram realizadas no Laboratório de Bromatologia do Departamento de Melhoramento e Nutrição Animal da Faculdade de Medicina Veterinária e Zootecnia - FMVZ - UNESP - Campus de Botucatu. A análise de taninos totais foi realizada pelo Laboratório de Alta Tecnologia (Labtec-Mogiana Alimentos AS, Campinas-SP).

A digestibilidade aparente de energia e nutrientes do farelo de canola foi calculadz de acordo com o as equações descritas por FURUYA et al. (1999). A dieta teste substituiu 30\% da dieta referência purificada. A análise de óxido de crômio foi realizada no Laboratório de Química Analítica do Departamento de Química do Instituto de Biociências da UNESP - Campus de Botucatu, de acordo com GRANER et al. (1972).

\section{Resultados e Discussão}

Durante o período de coleta, foram encontrados valores médios de $26,35 \pm 2,47^{\circ} \mathrm{C} ; 7,21 \pm 0,84$; $4,82 \pm 1,77 \mathrm{mg} / \mathrm{L}$ e $0,12 \pm 0,01 \mathrm{mg} / \mathrm{L}$ nos aquários de alimentaçãoe $26,67 \pm 3,26^{\circ} \mathrm{C} ; 7,18 \pm 0,58 ; 5,44 \pm 1,28 \mathrm{mg} / \mathrm{L}$ e $0,02 \pm 0,01 \mathrm{mg} / \mathrm{L}$, nos aquários de digestibilidade, respectivamente, para a temperatura, $\mathrm{pH}$, oxigênio dissolvido e amônia total.

Na Tabela 2 encontra-se a composição química da dieta referência e do farelo de canola (FC), respectivamente. O nível de fibra bruta e as exigências de cálcio e fósforo da dieta referência encontram-se dentro dos valores recomendados pelo NATIONAL RESEARCH COUNCIL - NRC (1993) para tilápias. Ressalta-se que o elevado nível de fibra bruta $(9,02 \%)$ e taninos totais $(1,18 \%)$ do FC pode afetar negativamente a digestibilidade.

Na Tabela 3 encontram-se os valores de digestibilidade aparente (DA) da energia e nutrientes da dieta referência e do FC.

A DA da matéria seca da dieta referência aproximou-se dos valores encontrados por SUGIURA et al. (1998), com dieta referência formulada com base em proteína da caseína para o salmão (Oncorhynchus kisutch) e truta arco-íris (Oncorhynchus mykiss), que obtiveram valores de 81 e $83,7 \%$ de DA da matéria seca, respectivamente, para essas espécies. A DA da matéria seca do FC foi superior à encontrada por HILTON e SLINGER (1986) com a truta arco-íris, de 60,4\%. 
Tabela 2 - Composição química $(\bar{x} \pm \sigma)^{1}$ da dieta referência e do farelo de canola (base na matéria natural)

Table 2 - Chemical composition $(x \pm \sigma)$ of reference diet and canola meal (as fed basis)

\begin{tabular}{|c|c|c|}
\hline $\begin{array}{l}\text { Composição }^{2} \\
\text { Composition }\end{array}$ & $\begin{array}{c}\text { Dieta referência } \\
\text { Reference diet }\end{array}$ & $\begin{array}{l}\text { Farelo de canola } \\
\quad \text { Canola meal }\end{array}$ \\
\hline Matéria seca (\%) & $90,70 \pm 0,19$ & $89,88 \pm 0,26$ \\
\hline $\begin{array}{l}\text { Dry matter } \\
\text { Energia bruta }(\mathrm{kcal} / \mathrm{kg})\end{array}$ & $4218,90 \pm 37,50$ & $4125,37 \pm 25,13$ \\
\hline $\begin{array}{l}\text { Gross energy } \\
\text { Proteína bruta }(\%) \\
\text { Crude protein }\end{array}$ & $33,63 \pm 0,13$ & $37,51 \pm 0,28$ \\
\hline $\begin{array}{l}\text { Fibra bruta }(\%) \\
\text { Crude fiber }\end{array}$ & $4,09 \pm 0,05$ & $9,02 \pm 0,08$ \\
\hline $\begin{array}{l}\text { Extrato etéreo }(\%) \\
\text { Ether extract }\end{array}$ & $6,57 \pm 0,08$ & $1,36 \pm 0,11$ \\
\hline $\begin{array}{l}\text { Cálcio(\%) } \\
\text { Calcium }\end{array}$ & $0,73 \pm 0,05$ & $0,61 \pm 0,03$ \\
\hline $\begin{array}{l}\text { Fósforo total (\%) } \\
\text { Total phosphorus }\end{array}$ & $0,74 \pm 0,03$ & $0,93 \pm 0,04$ \\
\hline $\begin{array}{l}{ }^{1} \text { Média } \pm \text { desvio-padrão } \\
\text { deviation of four replicates). } \\
2 \text { Valores determinados e } \\
\text { SP), de acordo coma metc } \\
\text { at Laboratory [FMVZ/UNESF } \\
3 \text { Farelo de canola (glicos } \\
1,18 \% \text { ), valores determin } \\
\text { SP) (Canola meal (glicosinol } \\
\text { were determined at Laborato }\end{array}$ & $\begin{array}{l}\text { de quatro repe } \\
\text { em laboratório (FI } \\
\text { todologia de SILVA } \\
S P, \text { Botucatu-SP], acc } \\
\text { sinolatos }=7 \mu \mathrm{m} \\
\text { inados em laboratc } \\
\text { olates }=7 \mu \text { moles } / g \text {; tc } \\
\text { tory [Labtec, Campina }\end{array}$ & $\begin{array}{l}\text { Zes (Mean } \pm \text { standard } \\
\text { Z/UNESP, Botucatu- } \\
\text { 990) (Values determined } \\
\text { ding to SILVA [1990]). } \\
\text { s/g; taninos totais = } \\
\text { (Labtec, Campinas- } \\
\text { tannins }=1.18 \% \text { ), values } \\
\text { P]). }\end{array}$ \\
\hline
\end{tabular}

Tabela 3 - Digestibilidade aparente $(\bar{x} \pm \sigma)$ * da energia e nutrientes da dieta referência e farelo de canola (base na matéria natural)

Table 3 - Apparent digestibility $(\bar{x} \pm \sigma)$ * of energy and nutrients of reference diet and canola meal (as fed basis)

\begin{tabular}{lcc}
\hline $\begin{array}{l}\text { Composição } \\
\text { Composition }\end{array}$ & $\begin{array}{c}\text { Dietareferência } \\
\text { Reference diet }\end{array}$ & $\begin{array}{c}\text { Farelo de canola } \\
\text { Canola meal }\end{array}$ \\
\hline $\begin{array}{l}\text { Matéria seca (\%) } \\
\text { Dry matter }\end{array}$ & $83,57 \pm 0,42$ & $77,84 \pm 3,14$ \\
$\begin{array}{l}\text { Energia bruta }(\mathrm{kcal} / \mathrm{kg}) \\
\text { Gross energy }\end{array}$ & $82,42 \pm 0,84$ & $71,99 \pm 1,61$ \\
$\begin{array}{l}\text { Proteína bruta (\%) } \\
\text { Crude protein }\end{array}$ & $94,14 \pm 0,26$ & $86,92 \pm 1,62$ \\
$\begin{array}{l}\text { Fibra bruta (\%) } \\
\text { Crude fiber }\end{array}$ & - & - \\
$\begin{array}{l}\text { Extrato etéreo (\%) } \\
\text { Ether extract }\end{array}$ & $93,01 \pm 0,11$ & $88,19 \pm 0,66$ \\
$\begin{array}{l}\text { Cálcio }(\%) \\
\text { Calcium }\end{array}$ & $86,17 \pm 1,44$ & $67,16 \pm 1,63$ \\
$\begin{array}{l}\text { Fósforo total (\%) } \\
\text { Total phosphorus }\end{array}$ & $59,68 \pm 1,35$ & $29,86 \pm 0,85$ \\
$\begin{array}{l}{ }^{*} \text { Média } \pm \text { desvio-padrão de quatro repetições. } \\
\text { *Mean } \pm \text { standard deviation of four replicates. }\end{array}$ &
\end{tabular}

A DA da energia do FC (72\%) foi semelhante à encontrada para esse ingrediente por HILTON e SLINGER (1986), em estudo realizado com a truta arco-íris, sendo superior à obtida por HAJEN et al. (1993) com o salmão (Oncorhynchus tshawytscha), aproximando-se dos valores determinados por WILSON e POE (1985) com o bagre do canal (Ictalurus punctatus) e FAGBENRO (1998) com a tilápia do Nilo, sendo superior ao obtido por HANLEY (1987) com a tilápia do Nilo e inferior ao descrito por KHAN (1994) com o bagre tropical (Mystus nemurus) e DEGANI et al. (1997) com a carpa comum, para o farelo de soja.

Com relação à DA da proteína, o valor encontrado no presente estudo $(86,92 \%)$ aproxima-se dos obtidos por HILTON e SLINGER (1986) com a truta arcoíris e HOSSAIN e JAUNCEY (1989) com a carpa comum, para o farelo de colza, e HAJEN et al. (1993), com o salmão (Oncorhynchus tshawytscha), para o FC originado de um cultivar isento de glicosinolatos, sendo superior ao encontrado por ANDERSON et al. (1992), em trabalho realizado com o salmão (Salmo salar), que encontraram valores de DA de 87,$1 ; 85,3 ; 87,9$ e $74,1 \%$, respectivamente.

Os resultados obtidos no presente trabalho reforçam as citações de KUBARIK (1997) e STICKNEY (1997) de que as tilápias possuem adaptações morfológicas e fisiológicas que favorecem a utilização de alimentos de origem vegetal, o que também foi observado por DEGANI e REVACH (1991) e FURUYA et al. (1997), em estudo avaliando o desempenho produtivo e por FURUYA et al. (1999), avaliando a DA dos aminoácidos essenciais desse ingrediente.

A menor DA da proteína do FC, obtido em salmonídeos, pode estar relacionada com o maior nível de fibra bruta presente em relação ao farelo de soja, que, segundo HILTON e SLINGER (1986), pode reduzir o aproveitamento da energia, da proteína e dos minerais. Além disso, a presença de taninos e fósforo fítico no FC pode aumentar a excreção de nitrogênio (RICHIE e BROWN, 1996).

A fração fibra bruta não foi utilizada, apesar de sua importância para se obter adequado funcionamento do trato digestório. As tilápias podem utilizar níveis mais elevados de inclusão de fontes protéicas como o FC, uma vez que níveis de fibra bruta de até $6 \%$ não reduzem o desempenho (NRC, 1993). Já a 
Rev. bras. zootec.

DA dos lipídios $(88,19 \%)$ foi inferior à descrita por HILTON e SLINGER (1986), que foi de 92,5\% para a truta arco-íris, e por HOSSAIN et al. (1997), que foi de 91,95\% para o "rohu" (Labeo rohita), concordando com as afirmações de DEGANI e REVACH (1991) de que as tilápias, em relação aos peixes carnívoros, utilizam menos eficientemente os lipídios, provavelmente pelo menor teor desse nutriente na sua dieta natural.

A disponibilidade do cálcio $(86,17 \%)$ do FC encontrada no presente estudo foi superior ao valor encontrado por SUGIURA et al. (1998), para o salmão (Salmo salar), que foi de $28 \%$. Quanto ao fósforo, os resultados do presente demonstraram baixa disponibilidade desse nutriente no FC, que foi de $29,86 \%$, confirmando a baixa eficiência dos peixes em utilizarem o fósforo fítico, o que também foi observado por SUGIURA et al. (1999), em trabalho realizado com a truta arco-íris.

Considerando-se que a única fonte de minerais (cálcio e fósforo) da dieta referência foi suplementada através do fosfato bicálcico, pode-se dizer que os valores de cálcio e fósforo determinados para a mesma, de 86,17 e 59,68\%, respectivamente, referem-se aos valores do fosfato bicálcico.

De forma geral, considerando-se as diferenças entre as espécies, condições experimentais, sistema de coleta de fezes e tipo de dieta, aparentemente, os elevados níveis de fibra e taninos são os fatores mais limitantes na utilização do FC, uma vez que foi utilizado FC com baixos níveis de glicosinolatos, que, segundo BELL (1993) e TESKEREDZIC et al. (1995), caso não haja adequada inativação, se torna o primeiro fator limitante para sua utilização. Os ingredientes com elevados teores de fibra caracterizam-se pela menor DA de nutrientes, como pode ser observado nos trabalhos de HANLEY (1987) e DEGANI et al. (1997) com tilápias e ERFANULLAH-JAFRI (1998) com carpas, sendo que os taninos podem elevar a excreção de nitrogênio.

A relação energia:proteína da dieta referência permaneceu próxima dos valores recomendados pelo NRC (1993), para as tilápias.

$\mathrm{O}$ conhecimento da energia digestível e da DA dos nutrientes do FC permite sua melhor utilização, possibilitando a elaboração de dietas mais precisa. Pelos resultados obtidos no presente trabalho, o FC demonstrou ser um alimento com potencial para ser utilizado na alimentação da tilápia do Nilo, como já demonstrado por FURUYA et al. (1997), em trabalho avaliando a inclusão de diferentes níveis desse in-
615

Tabela 4 - Matéria seca, energia e nutrientes digestíveis da dieta referência e do farelo de canola (base na matéria natural)

Table 4 - Reference diet and canola meal digestible dry matter, energy and nutrients (as fed basis)

\begin{tabular}{lcc}
\hline $\begin{array}{l}\text { Composição } \\
\text { Composition }\end{array}$ & $\begin{array}{c}\text { Dieta referência } \\
\text { Reference diet }\end{array}$ & $\begin{array}{c}\text { Farelo de canola } \\
\text { Canola meal }\end{array}$ \\
\hline $\begin{array}{l}\text { Matéria seca (\%) } \\
\text { Dry matter }\end{array}$ & $75,80 \pm 0,41$ & $69,97 \pm 2,85$ \\
$\begin{array}{l}\text { Energiabruta(kcal/kg) } \\
\text { Gross energy }\end{array}$ & $3477,22 \pm 23,71$ & $2969,98 \pm 84,20$ \\
$\begin{array}{l}\text { Proteína bruta (\%) } \\
\text { Crude protein }\end{array}$ & $31,66 \pm 0,20$ & $32,60 \pm 0,65$ \\
$\begin{array}{l}\text { Fibra bruta }(\%) \\
\text { Crude fiber }\end{array}$ & - & - \\
$\begin{array}{l}\text { Extrato etéreo (\%) } \\
\text { Ether extract }\end{array}$ & $6,11 \pm 0,07$ & $1,20 \pm 0,11$ \\
$\begin{array}{l}\text { Cálcio }(\%) \\
\text { Calcium }\end{array}$ & $0,63 \pm 0,05$ & $0,41 \pm 0,03$ \\
$\begin{array}{l}\text { Fósforo total (\%) } \\
\text { Total phosphorus }\end{array}$ & $0,44 \pm 0,02$ & $0,28 \pm 0,01$ \\
\hline
\end{tabular}

* Média \pm desvio-padrão de quatro repetições.

* Mean \pm standard deviation of four replicates.

grediente em dietas para a tilápia do Nilo durante a fase de reversão. Esses autores concluíram que esse alimento pode ser incluído em até 19,7\% para essa espécie.

Quando da substituição de FC por outra fonte protéica convencional ou alternativa, os níveis de fibra, glicosinolatos e taninos devem ser observados, uma vez que podem sofrer alterações de acordo com a variedade e/ou processamento utilizado para obtenção do farelo.

\section{Conclusões}

Para a tilápia do Nilo (Oreochromis niloticus), observaram-se valores de 77,84; 71,99; 86,92; 88,19; 67,16 e $29,86 \%$ de digestibilidade aparente, para a matéria seca, energia bruta, proteína, lipídios, cálcio e fósforo, respectivamente, para o farelo de canola.

O cálcio e fósforo do fosfato bicálcico apresentaram disponibilidade de 86,17 e $59,68 \%$, respectivamente.

\section{Referências Bibliográficas}

ANDERSON, J.S., LALL, S.P., ANDERSON, D.M. et al. 1992. Apparent and true availability of amino acids from commom feed ingredients for Atlantic salmon (Salmo salar) reared in sea water. Aquaculture, 108:111-114.

BELL, J. M., KEITH, M. O. 1991. A survey of variation in the quimical composition of commercial canola meal produced in Western Canadian crushing plants. Can. J. Anim. Sci., 71(2):469-480. 
BELL, J.M. 1993. Factor affecting the nutritional value of canola meal: a review. Can. J. Anim. Sci., 73(3):679-697.

DEGANI, G., REVACH, A. 1991. Digestive capabilities of three commensal fish species: carp, Cyprinus carpio L., tilápia, Oreochromis aureus x O. niloticus, and African catfish, Clarias gariepinus (Burchell, 1882). Aquaculture and Fischeries Management, 22:397-403.

DEGANI, G., VIOLA, S., YEHUDA, Y. 1997. Apparent digestibility of protein and carbohydrate in feed ingredients for adult tilapia (Oreochromis aureus $x$ O. niloticus). Israeli J. Aquac., 49(3):115-123.

ERFANULLAH-JAFRI, A.K. 1998. Evaluation of digestibility coefficients of some carbohudrate-rich feedstuffs for Indian major carp fingerlings. Aquac. Res., 29:511-519.

FAGBENRO, O.A. 1998. Apparent digestibility of various legume seed meals in Nile tilapia diets. Aquac. Intern., 6:83-87.

FURUYA, V.R.B., HAYASHI, C.E, FURUYA, W.M. 1997. Farelo de canola na alimentação da tilápia do Nilo (Oreochromis niloticus), durante o período de revesão de sexo. Revista da Sociedade Brasileira de Zootecnia, 26(6):1067-1073.

FURUYA, W.M., PEZZATO, L.E., FURUYA, V.R.B. et al. 1999. Digestibilidade aparente da proteína e aminoácidos do farelo de canola pela tilápia do Nilo, Oreochromis niloticus. In: ACUICULTURA VENEZUELA, 1999, Puerto La Cruz. Memorias... Puerto La Cruz: WAS/ASA/SVA/USB, 1999. p.206-217.

GRANER, C.A.F. Determinação do crômio pelo método colorimétrico da s-difenilcarbazida. Botucatu-SP: UNESP, 1972. 112p. Tese (Doutorado em Ciências) - Faculdade de Ciências Médicas e Biológicas, Universidade Estadual Paulista, 1972.

HAJEN, W.E., HIGGS, D. A., BEAMES, R.M. et al. 1993. Digestibility of various feedstuffs by pos-juvenile chinook salmon (Oncorhynchus tshawytscha) in sea water. 2. Measurement of digestibility. Aquaculture, 113:333-348.

HANLEY, F. 1987. The digestibility of foodstuffs na the effects of feeding selectivity on digestibility determination in tilapia, Oreochromis niloticus (L.). Aquaculture, 66:163-179.

HILTON, J.W., SLINGER, S.J. 1986. Digestibility and utilization of canola meal in practical-type diets for rainbow trout (Salmo gairdneri). Can. J. Fisheries Aquatic. Sci., 43:1149-1155.

HOSSAIN, M.A., JAUNCEY, K. 1989. Studies on the protein, energy and amino acids digestibility of fish meal, mustard oilcake, linseed na sesame meal for common carp (Cyprinus carpio). Aquaculture, 83:59-72.

HOSSAIN, M.A., NAHAR, N., KAMAL, M. 1997. Nutrient digestibility coefficients of some plant and animal proteína for rohu (Labeo rohita). Aquaculture, 151:37-45.
KHAN, M.S. 1994. Apparent digestibility coefficients for commom feed ingredients in formulated diets for tropical catfish, Mystus nemurus (Cuvier \& Valencienes). Aquac. Fisheries Manag., 25:167-174.

KUBARIK, J. 1997. Tilapia on highly flexible diets. Feed International, 6:16-18.

MUZTAR, J.A., SLINGER, S.J. 1982. The true metabilizable energy and amino acids of Candle, Altex and Regent canola meals. Can. J. Anim. Sci., 62(2):521-525.

NATIONAL RESEARCH COUNCIL - NRC. 1993. Nutritional requirements of fishes. Washington: Academic Press. 114p.

RICHIE, M.; BROWN, P.B. 1996. Availability of phosphorus from feedstuffs fed to rainbow trout, Oncorhynchus mykiss. Aquaculture, 142:269-282.

SANTOS, A.C., BASSO, L.C. 1990. Composição química e qualidade nutricional do concentrado protéico de colza. Arquivos de Biologia e Tecnologia, 33(4):879-893.

STICKNEY, R.R. 1997. Tilapia nutrition, feeds and feeding. In: COSTA-PIERCE, B.A., RAKOCKY, J.E. (Eds.) Tilapia aquaculture in the Americas. v.1, WAS, Baton Rouge. p.34-54.

SUGIURA, S.H., DONG, F.M., RATHBONE, C.K. et al. 1998. Apparent protein digestibility and mineral availabilities in various feed ingredients for salmonid feeds. Aquaculture, 159:177-202.

SUGIURA, S.H., RABOY, V., YOUNG, K.A. et al. 1999. Availability of phosphorus trace elements in low-phytate varieties of barley and corn for rainbow trout (Oncorhynchus mykiss). Aquaculture, 70(3/4):285-296.

TESKEREDZIC, Z., HIGGS, D.A., DOSANJH, B.S. et al. 1995. Assessment of undephytinized and dephytinized rapeseed protein concentrate as souces of dietary protein for juvenile rainbow trout (Oncorhynchus mykiss). Aquaculture, 131(2):261-277.

WILSON, R.P., POE, W.E. 1985. Apparent digestible protein and energy coefficients of common feed ingredients for channel catfish. Progessive Fisheries Culturist, 47(3):154-158.

YAMAMOTO, T., IKEDA, K., UNUMA, T. et al. 1997. Apparent availabilities of amino acids and minerals from several protein sources for fingerling rainbow trout. Fisheries Sci., 63(6):995-1001.

Recebido em: 08/06/00

Aceito em: 22/12/00 